\title{
Assessment for Successful Intelligence: A Paradigm Shift in Classroom Practice
}

John Mary Vianney Mitana ${ }^{1}$ Anthony Mugagga Muwagga ${ }^{2}$, Cornelius Ssempala ${ }^{3}$

\begin{tabular}{l} 
ARTICLE INFO \\
\hline Article History: \\
Received \\
19.09.2018 \\
Received in revised \\
form 29.11.2018 \\
Accepted \\
Available online \\
01.01.2019
\end{tabular}

\begin{abstract}
Conventional educational assessments favour individuals who are strong in memory and analytical abilities. This is based on a longstanding theory of a general intelligence (g). Alternative intelligence theories have however revealed that success in life requires skills beyond memory and analytical skills. This article presents an analysis of Sternberg's theory of successful intelligence. Sternberg defines intelligence as one's ability to achieve one's goals in life, given one's social-cultural context; by capitalising on strengths and correcting or compensating for weaknesses in order to adapt, shape and select environments through a combination of analytical, creative and practical skills. This article is divided into four main parts. It starts with an introduction to the conceptual definition of intelligence. Then it discusses Sternberg's theory of successful intelligence. Next, it discusses assessment for successful intelligence in a classroom. Finally, it draws conclusions.
\end{abstract}

\section{Keywords:}

(C) IJERE. All rights reserved

General intelligence, intelligence, multidimensionality, classroom assessment, assessment for successful intelligence.

\section{INTRODUCTION}

A single or general intelligence theory has greatly influenced the inquiry into theories of cognition and educational assessment till the present day (Postlethwaite, 2011). In a theory of a general intelligence, Spearman argued that there is a general factor $g$, which is a latent variable that is a measures of cognitive capacity (Postlethwaite, 2011; Spearman, 1904). He argued that the general factor is predictive of human achievement in school and beyond. Consequently, most achievement and intelligence tests are often based on the general factor (g), (Williams, Zimmerman, Zumbo, \& Ross, 2003). Intelligence Quotient (IQ) tests such as Wechsler Adult Intelligence Scale, and Standford-Binet Intelligence Test are also based on a general intelligence theory. The theory has equally influenced classroom tests and assessments. Most of these tests and assessments are at worst skewed

\footnotetext{
1. PhD Candidate, School of Education, College of Education and external Studies, Makerere University. Principal, Luigi Giussani Institute of Higher Education

2. Associate Professor, School of Education, College of Education and External Studies, Makerere University

3. Senior Lecturer, School of Education, College of Education and External Studies, Makerere University

Corresponding e-mail: mitanavianney@yahoo.com, orcid.org/0000-0002-7553-7369
} 
towards the measurement of students' memory and at best analytical/critical thinking abilities. In the past quarter century, however, the theory of a general intelligence has come under considerable criticism. Critics of a general intelligence theory such as Cattell (1971), Sternberg (1982, 1985, 2005), and Gardner (1983, 1999) have proposed alternative theories. Cattell's (1971), advanced a hierarchical model of two general subfactors of intelligence namely fluid intelligence and crystallised intelligence; Sternberg's (1982) theory of successful intelligence and; Gardner's (1983) theory of multiple intelligence. Kaufman \& Singer (2004) have argued that the intelligence theories after the Spearman's (1904) general intelligence theory have considerably advanced the developments in the intelligence theory, assessment and research. Similarly, Otaciuoglu (2016) has argued that learners do not attribute success to the same factors. He further argues that individual differences influence learner-success. Otaciuoglu's argument is in agreement with that of Akcaalan (2016) who argues that life-long learning greatly contributes to human success. Akcaalan considers life-long learning as key to human success especially in the 21st century because it enables one to emplace and make use of the ever increasing levels of information. In this theoretical article, we argue that the assessment for the successful intelligence enriches classroom practice.

\section{Methodology}

In this theoretical article, we use the available literature to define the successful theory of intelligence. We explain how the successful theory of intelligence is a better option, than the general factor theory of intelligence, in assessing students' ability to navigate life situations. We thus use Sternberg's theory to give a detailed account on how teachers can apply the theory in the classroom setting to assess learner's ability to cope with life situations.

\section{The theory of Successful Intelligence}

Sternberg was not satisfied with Spearman's (1904) view of a general intelligence. He argued against the conventional intelligence theory and its overemphasis of the importance of human memory and analytical abilities. He argued that human intelligence goes beyond the ability to memorise and analyse information. He thus defined intelligence as

The ability to achieve one's goals in life, given one's social-cultural context; by capitalising on strengths and correcting or compensating for weaknesses in order to adapt, shape and select environments through a combination of analytical, creative and practical skills (Sternberg, 2005, p. 189).

Sternberg (2005) argued that the traditional views on human intelligence, instruction and assessment, based on a general intelligence, are unfair to individuals who are gifted in 
other abilities. His theory is based on the argument that classroom assessments grounded on a general intelligence theory overemphasise memory and analytical skills. In reality, he argues, a person requires skills beyond memory and analytical abilities. He thus proposed the successful theory of intelligence which later came to be known as the triarchic theory of human intelligence (Sternberg, 1985) because of its emphasis on three main skills categories: analytical skills, creative skills and practical skills. In a classroom context, the teacher needs to ensure that students are appropriately and consistently developing, not only the memory and analytical skills but also, the analytical, creative and practical skills.

Sternberg (2003, 2005) argues that the three main skills (ability) categories are independent of one another and require students to develop different capabilities. Analytical skills assessment would require students to apply their thinking skills to "fairly familiar kind of problems which are abstracted from everyday life" (Sternberg, 2005, p.191). Creative skills would be called for to show students' ability to apply their knowledge and skills to tasks and situations that are relatively novel and unconventional. Practical skills, on the other hand, would be invoked during assessment in tasks and situations that require students to adapt, shape and select environments (Sternberg, 2005). This implies to the teacher that he/she balances classroom skills categories. For example, a teacher might consider formulating questions that test students' masterly of analytical, creative and practical abilities.

The successful intelligence theory implies to a classroom teacher that he/she is aware of the fact that intelligence is predictive not only of the school achievement and success but also life beyond school (Hunt, 2008; Kaufman \& Singer 2004). Recent studies (Gates et al., 2016; Lippman Ryberb, Caney \& Moore, 2015; Sternberg, 2003) have shown that the predictive measure of the quality of a person's success cannot be limited to his/her memory or analytical skills. Rather, a person's success requires the ability to achieve one's life goals. This means success beyond school including the world of work. Sternberg (2003) has argued that the conventional assessment system is unfair to students who do not succeed in a aparticular career preparation track but who could have the ability to succeed elsewhere.

\section{Assessment for successful intelligence in a classroom}

Sternberg's theory of successful intelligence has significant implication to classroom practice. This is particularly in the area of assessment for learning. In this article, we define assessment for learning as the process of gathering information about what students know and what they do not know; what they can do and what they cannot do for purposes of informing the teaching and learning processes. Precisely this means classroom based assessments aimed at enhancing students' successful intelligence. 
In this article we refer to how teachers can test and assess students' knowledge and application of successful intelligence. Sternberg (2005, p. 189) defines successful intelligence in terms of ability to; 1) achieve one's goals in life given one's social-cultural context; 2) by capitalising on strengths and correcting or compensating for weaknesses; 3) in order to adapt, shape and select environments; and, 4) through a combination of analytical, creative and practical skills. Assessment for successful intelligence therefore involves the process of collecting information about students' abilities to achieve their goals in their social-cultural context to inform the classroom practice. Classroom practice includes all activities aimed at enhancing students' ability to achieve their goals in life given their social-cultural context. The part below discusses assessment for successful intelligence in terms of the four major aspects of Sternberg's definition of successful intelligence.

\section{Ability to achieve one's goals in life given one's social-cultural context}

Several studies have investigated the attitudes of teachers and prospective undergraduate teachers towards Sternberg argues that intelligence connotes a "somewhat different thing to each individual" (Sternberg, 2005 p. 189). This calls for contextualisation of assessment tests so that all students' backgrounds are catered for. This might entail using local and common language and expressions in the test items. For example, whereas it might be easy for students staying near a lake to answer a question: "analyse challenges faced by fishermen during the dry season", it is much difficult for students far off the lake. However, the latter may find it easy to pass questions on hunting if they stay within a hunting community.

Assessment for successful intelligence requires that the assessment tests are comprehensively fair enough to cater for individual student's life goals. Sternberg \& Grigorenko (2003) argue that multidimensional assessment options are used in order to cater for individual differences in students' life goals. Unidimensional assessments are usually unfair to some sections of students especially when their abilities are not tested but instead only their lacking skills are included in the test. For example, students with strong essay writing skills could be unfairly assessed if the entire assessment test is composed of multiple choice questions in which these students are weak. Multidimensional assessments including, for example, multiple choice questions, short essays, and structured questions might be useful to a teacher in assessing successful intelligence. Multidimensional assessments help a teacher to avoid the tedious individualised assessments which would have required a programme for each student. This would be time-consuming, counterproductive and at worst not practical in a typical classroom setting (see Sternberg \& Grigorenko, 2003). 
Assessment for successful intelligence further requires that the teacher takes keen interest and ability to assess whether or not an individual learner is able to coordinate and pursue the selected goals (Sternberg, Grigorenko, \& Zhang, 2008). Sternberg (2005) argues that assessing for successful intelligence is not just about measuring whether or not students are able to set life gaols but more importantly their ability to pursue them. An evaluation of intelligence should focus not on what goal is chosen but rather on whether the individual has chosen a worthwhile set of goals and shown the skills and dispositions needed to achieve them (Sternberg, 2005 p.189). In a classroom context, this might necessitate the teacher to make and keep observations and records about students' advancement in their life goals. However, this might need a clear knowledge and understanding of the students by the teacher. This normally happens where there is a close and positive teacher-student relationship which is less likely in developing countries in which there high student-teacher ratio.

\section{Ability to capitalise on one's strengths and correct or compensate for weaknesses}

Conventional theories of cognition and assessment are based on the argument that all students (people) have a "general" factor of intelligence (Spearman, 1904, 1927). This argument means that there is a general factor whose presence qualifies one as intelligent and its absence renders one unintelligent. However, the theory of successful intelligence recognizes that in reality, no person is good or bad at everything (Sternberg, 2000; Sternberg \& Grigorenko, 2002). This means that in assessment for successful intelligence students are assessed on various aspects of life, academic and non-academic. For example, teacher might need to collect information on how individual students participate in group discussion activities as well as those indicating leadership skills within the group. A student might portray high potential for leadership while scoring low in the real subject matter. Assessment for successful intelligence enables students to capitalise on their strength and correct or compensate for their weaknesses.

In communicating assessment feedback to the students, the parents, the school administration or other policy makers, successful intelligence requires that the teacher articulates students' areas of strength and areas of weakness. Articulating a student's areas of weakness might necessitate showing specific area he/she is working on and how much he/she is improving over time. Thus, choosing a way to communicate the assessment results is critical for a teacher. Articulating how much a student is working on a given skill becomes a source of motivation to work harder to improve on one's areas of strength as well as areas of weakness.

\section{Ability to adapt, shape and select environments}


The theory of successful intelligence "recognises that intelligence broadly defined refers to more than just adapting to the environment" (Sternberg, 2005 p. 190). Sternberg (2003) argues that education needs to help students to adapt to new environment especially in this new era of information technology in which everything seems to change all the time. In terms of assessment, the theory argues that students are tested and assessed on their ability to transfer knowledge and skills they have learnt from one environment to another or from one topic/subject to another (Sternberg, 2005). For example, in a history subject, students may be asked to explain the salient causes of the 1830 Belgian revolution using the knowledge acquired from the causes of the 1789 French revolution. In a mathematics class, the teacher may ask students to calculate the area of a pentagon. This may require the student to adapt the knowledge about calculating the area of a tringle to find the area of a triangle. However, adaption skills are not enough on their own. It requires to be balanced with shaping.

In shaping, one modifies the environment to fit what one seeks of it, rather than modifying oneself to fit the environment (Sternberg, 2005). Shaping includes to one's ability to recognise that one cannot adapt to everything around him/her. It also includes that ability to recognise the things one can modify for the better. Successful intelligence is thus partly about "deciding what to change, and then how to change it" (Sternberg, 2005 p. 190). This suggests that educational assessment goes beyond mere recall of the passively learnt information. The theory encourages teachers to test whether or not students are able to question the status-quo and take the risk of modifying it. For example a teacher might use question phrases like, in your view... in your own words, suggest... This might require the student to shape the available facts to come up with a new concept or solution The choice to adapt to or shape the environment necessitates a choice.

Successful intelligence recognises that occasionally one attempts unsuccessfully to adapt to and shape the environment (Sternberg, 2005). The theory suggests that the appropriate action might be to select another environment. In terms of educational assessment, this may mean that teachers test and assess students' ability to know when it is appropriate to select a new environment. This may for example take the form of selecting alternative subjects or even alternative elective questions during an examination. This could be an indicator of the ability to select environment.

\section{Ability to combine analytical, creative and practical skills}

Successful intelligence requires that all assessments are balanced in terms of the thinking skills (Sternberg \& Grigorenko 2003). According to Sternberg \& Grigorenko (2003), teachers need to avoid the false dicotomy between teaching for thinking and 
teaching for facts. They assert that memory is a preliquite of analystical, creative and practical abilities. For example, a student might not be able to analyse a text or information which he/she does not know. Similarly, one might not be able to creatively think about something he/she does not know. This is equally similar to putting skills or abiities into practice. Thus, assessing for successful intelligence requires that the classroom teacher considers a broader range of students' abilities than is typically measured by tests of intellectual and academic skills (Sternberg, 2005). Considering memory as well as higher level thinking ability questions is important for a classroom situation.

Like most of the conventional assessments, assessment for successful intelligence measures memory and analytical abilities. On the part of memory, they assess students' ability to recall and or recognise information. In terms of analytical abilities, they assess students' ability to analyse, compare and contrast, evaluate, critique, and judge (Sternberg, 2005; Sternberg \& Grigorenko, 2003). Considering assessment for analytical abilities in a geography lesson, a teacher may ask students to compare and contrast the formation of fold ranges mountains and block mountains. In a history class, a teacher may ask students to analyse what might have happened to France if the 1789 French revolution had not taken place. These are non-routine questions which measure students' ability to apply analytical skills instead of memorisation.

The successful intelligence theory recognises that analytical abilities are important in one's life. But the theory stresses that a person requires far more than analytical abilities to succeed in life. Sternberg $(1982,2005)$ argues that for a person to succeed in life he/she requires the ability to select a solution that is suitable to a particular contextual problem. In a classroom context, teachers need to assess students' ability to judge the appropriateness of a solution to a particular problem. A teacher might prepare a test in which there are a number of challenges and corresponding list of possible solutions. In this way, the students are asked to select the most appropriate solution to a particular problem.

In a classroom situation, assessing analytical, creative and practical skills might not be an easy task for a teacher. In this article, we propose sample action verbs which a teacher might choose a particular action verb to formulate assessment items during the teaching and learning. Below is a proposed list of sample action verbs which one could use to assess analytical, creative and practical ability. The prompt action verbs below are given in a non-hierarchical order. They merely indicate sample prompt action verbs which a teacher can use to assess analytical, creative and practical skills. 

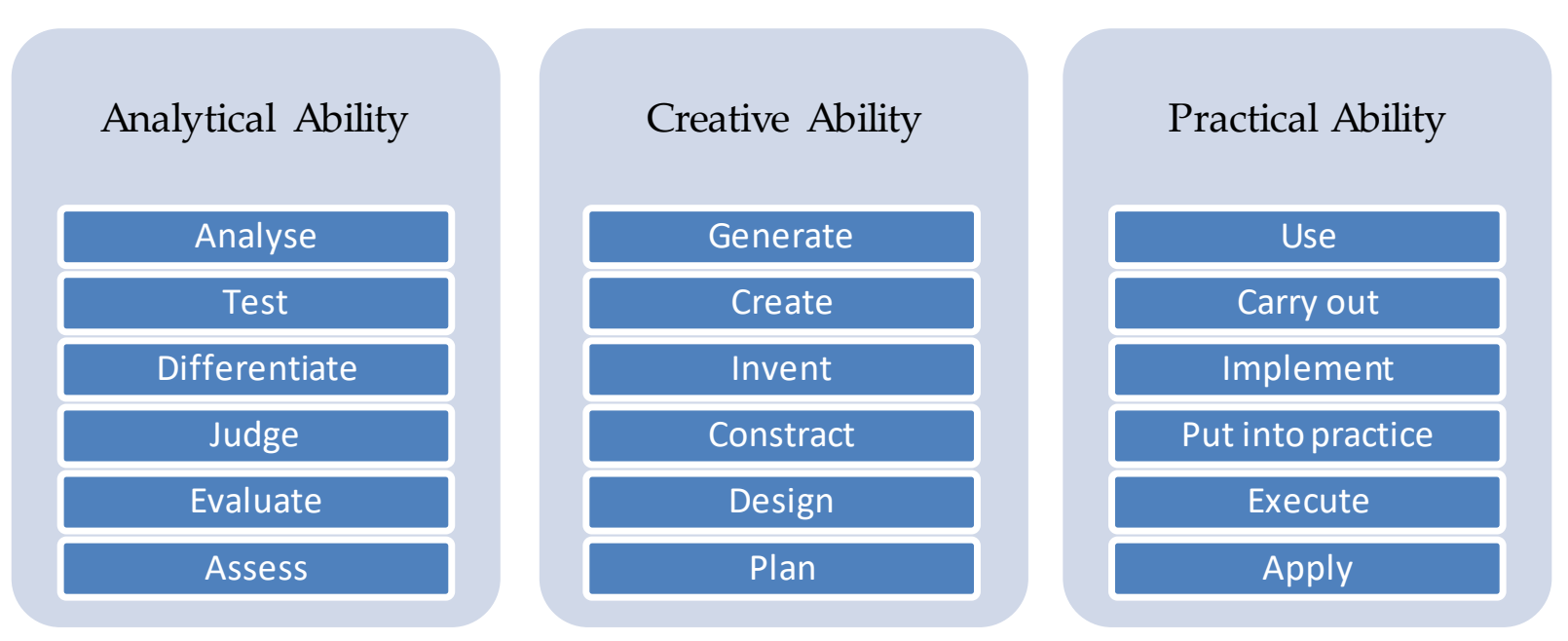

Figure 1: Examples of verbs to be used in assessment for successful intelligence

Analytical intelligence involves the ability to analyse, test, differentiate, judge, evaluate and assess information. Creative intelligence includes the ability to plan for, generate, create, invent, construct and design new information or project. On the other hand, practical intelligence includes one's ability to apply, put into practice and use information or execute implement and carry out a given project. Although, the analytical, creative and practical abilities are related, each of them may be exercised independent of the others. For example, one may have the ability to analyse or evaluate information but when he/she is not able to apply it. Similarly, one may invent or create a project but when he/she is not able to analyse it. However, we argue that in all cases, memory is important because one may not be able to analyse, apply or design what he/she does not know.

\section{Recommendations and Conclusions}

Teachers widely use, in their classrooms, conventional assessments based on the measurement of memory and analytical skills (Postlethwaite, 2011). This is however limited in terms of preparing students for life in and beyond the school (Sternberg, 2005). This article argues that Sternberg's theory of successful intelligence might be a better option for teachers to prepare students to achieve their goals in school and beyond school including the world of work. The adaption of Sternberg's theory of successful intelligence enables the classroom teacher to adjust the classroom practice to suit students' life goals given their sociocultural contexts.

Success means different things to different people depending on the sociocultural context (Sternberg \& Grigorenko, 2003). This article concludes that teachers need to consider students' backgrounds, contexts and life goals. Assessment for successful intelligence requires that students are tested on how ready they working towards their life goals in their particular contexts (Sternberg, 2005). The assessment data helps the teacher to design and redesign classroom activities aimed at enhancing students' successful intelligence. 
Mitana,J.M.V., Muwagga,A.M. \& Ssempala,C. (2018).Assessment for successful intelligence: a paradigm shift in classroom practice. International Journal of Educational Research Review,4(1),106-115.

Conventional unidimensional assessments are unfair to some sections of learners (Sternberg, 2005). This article argues that using the successful theory of intelligence in the classroom increases the multidimensionality of the assessment process and outlook. It also caters for individual differences in terms of life goals, sociocultural contexts and abilities (Sternberg \& Grigorenko, 2003). Using multidimensional assessments increases fairness of the assessment to the students.

\section{Limitations of the study}

Although the study was based on the interpretation of literature in relation to Ugandan context, no literature was found that was the use of successful intelligence in a Ugandan context. This study only forms a basis for an empirical study to assess learners' successful intelligence in Uganda.

\section{Recommendation for future studies}

We recommend an empirical study on the assessment of learners' successful intelligence and the use of such assessment data to inform classroom practice.

\section{REFERENCES}

Akcaalan, M. (2016). Investigating the relationship between lifelong learning and social emotional learning. InternationalJournal of Educational Research Review, 14-20.

Cattell, R. (1971). Abilities: Their structure, growth and action. Boston, USA: Houghton Mifflin.

Gardner, H. (1983). Frames of mind. New York: Basic Books.

Gardner, H. (1999). Intelligence reformed: Intelligences for the 21st Century. New York: Basic Books.

Gates, S., Lippman, L., Shadowen, N., Burke, H., Diener, O., \& Malkin, M. (2016). Key sost-skillsforcrosssectoral youth outcomes. USAID's YouthPower Implementation, YouthPower. Washingtoin DC.: YouthPower Action.

Hunt, E. (2008). Applying the theory of Successful Intelligence to education - The good, the bad and the ogre. Perspectives of PsychologicalScience, 3(6), 509 - 515.

Kaufman, S., \& Singer, J. (2004). Applying the theory of Successful Intelligence to Psychotherapy training and practice. Imagination, Cognition and Practice, 23(4), 325 - 355.

Lippman, L., Ryberg, R., Canrney, R., \& Moore, K. (2015). Key Soft-Skills thatfoster youthforce seccess: Towards a consesus across fields. Published through the workforce connections project managed by FHI 360 and funded by USAID. Washington DC: USAID, FHI 360, Child Trends.

Otacioglu, S. (2016). Determining the differences between academic success and perceptional levels of concervatory students. InternationalJournal of Educational Research Review, 8-17.

Postlethwaite, B. (2011). Fluid ability, crystallised ability and performance across multiple domains. A Mataanalysis. University of lowa. Retrieved April 19, 2018, from http://ir.uiowa.ed/etd255

Spearman, C. (1904). General Intelligence, objectively determined and measured. American Journal of Psychology, 15, 201-293. 
Sternberg, R. (1982). Natural, unnatural and supernatural concepts. Cognitive Psychology, 14, 451-488.

Sternberg, R. (1999). The theory of successful intelligence. Review of General Psychology, 3, 292-316.

Sternberg, R. (2003). Implications of the Theory of Successful Intelligence for Career Choice and Development. Journal of Career Assessment, 11(3), 136-152. doi:10.1177/1069072703251610

Sternberg, R. (2005). The theory of successful intelligence. Interamerican Journal of Psychology, 39(2), 189202.

Sternberg, R., \& Grigorenko, E. (2003). Teaching for successful intelligence: Principles, Procedures and Practices. Journalfor the Education of the Gifted, 207-228.

Sternberg, R., \& Grigorenko, E. L. (2006). Cultural intelligence and successful intelligence. Group and Organisation Management, 31(1), 27 - 39. doi:10.1177/1059601105

Williams, R. W., Zimmerman, D., Zumbo, B., \& Ross, D. (2003). Charles Spearman: British behavioural scientist. Human Nature, 3(2003), 114-118. 